\title{
Gestational, perinatal, and postnatal factors that interfere with practice of exclusive breastfeeding by six months after birth
}

Mariana Moraes de Oliveira ${ }^{1,2^{*}}$ and José Simon Camelo $\mathrm{Jr}^{1}$

\begin{abstract}
Background: Despite evidences indicating the superiority of breastfeeding and recent advances in the indicators of breastfeeding in Brazil, exclusive breastfeeding (EBF) during the first six months after birth continues to be an infrequent practice in the country. The objective of the present study was to determine which gestational, perinatal, and postnatal factors of the mother-baby dyad might be associated with the cessation of EBF by six months after birth.

Methods: Data were collected at the rooming-in facility of the Reference Center of Women's Health of Ribeirão Preto-Mater (CRSM-Mater) during the postpartum period (24 to $72 \mathrm{~h}$ after birth) from December 2012 to April 2013 and by telephone contact between the researcher and participating mothers by six months after birth. Questionnaires were applied to collect data, such as the practice of EBF in the last $24 \mathrm{~h}$ in the sixth month after birth. The hierarchical theoretical model was proposed and data were analyzed statistically by log-binomial regression models using SAS 9.3.
\end{abstract}

Results: The study involved 283 mother-baby dyads in which the mother evaluated did not present pregnancy-puerperal complications that could impede breastfeeding and confirmed the interest in breastfeeding her child. After the telephone contact in the exact sixth month after the birth of each participating baby, $84.8 \%$ of the participating mothers reported that they were no longer exclusively breastfeeding their babies. After statistical analysis, we found that there was a significant association between cessation of EBF and maternal report of previous experience with EBF for one month $(0.91,95 \% \mathrm{Cl} 0$. $81,0.99)$ and six months $(0.81 ; 95 \% \mathrm{Cl} 0.68,0.94)$. These practices were associated with the maintenance of EBF and, even after adjustment for maternal socio-demographic variables, this association was maintained $(0.85 ; 95 \% \mathrm{Cl} 0.73,0.99)$. Thus, there is a greater chance of practicing and maintaining EBF by six months after birth when mother had previous experience with it.

Conclusion: The identification of the risk variables associated with cessation of EBF by six months postpartum, such as previous experience with exclusive breastfeeding, may contribute to the effectiveness of EBF intervention and support measures during the first six months after birth.

Keywords: Breastfeeding, Exclusive breastfeeding, Weaning

\footnotetext{
* Correspondence: mariana.m.oli@usp.br

'Department of Pediatrics, Ribeirão Preto Medical School, University of São Paulo, Ribeirão Preto, São Paulo, Brazil

${ }^{2}$ Faculdade de Medicina de Ribeirao Preto, Departamento de Puericultura e

Pediatria, Universidade de São Paulo, Avenida Bandeirantes, 3900, Monte

Alegre, Ribeirao Preto, São Paulo, SP 14048-900, Brazil
} 


\section{Background}

Despite scientific evidence regarding the benefits and superiority of human milk (HM) as well as the harmful effects of infant formulas, the practice of exclusive breastfeeding $(\mathrm{EBF})$ is still infrequent in Brazil. Even with the consolidation of numerous strategies to promote breastfeeding (BF) and the general public health recommendation that infants should be exclusively breastfed during the first six months of life in order to achieve good growth and development, the percentage of infants exclusively breastfed for the first six months of life is still low and worrisome [1-11].

A cross-sectional study conducted in the late 1990s in Brazil found alarming data on the estimated prevalence of EBF in the last $24 \mathrm{~h}$ by age of the child, showing that of 1259 children aged between 15 and 45 days of life, only $47.5 \%$ were In EBF [12].

In addition to this previous study, an important national survey entitled "National Survey of Demography and Health of Children and Women (PNDS) 2006" evaluated a sample of 4817 children considered to be representative of the Brazilian population and found that $42.9 \%$ were breastfed up to one hour after And that $48.3 \%$ of children aged 2-3 months were in EBF in the last $24 \mathrm{~h}$ [2].

The low EBF prevalence can be explained by sociocultural influences related to the industrialization process, such as the increasing commercialization of breast milk substitutes and the increase in female participation in the labor market. With the absence of women, the resources used to feed their children include bottles; milk from animal sources, such as cows; and industrialized infant formulas $[10,13-15]$. The progressive substitution of breast milk as the sole source of nutrition, has had disastrous consequences for the health of babies since $\mathrm{HM}$ is a source of energy, nutrients, and bioactive factors, and is an environmental determinant of adequate intestinal colonization childhood, which favors the protection and defense of children against infections and diseases, as well as the physical, cognitive, and emotional development of the child [1, 4, 6, 16-21].

In addition, the low prevalence of BF in Brazil can be explained by the fact that BF is a biologically determined, yet culturally and socially conditioned, practice that makes the BF experience complex because it involves biological, psychological, and social factors related to both mother and their child [22-25]. Thus, considering that EBF can be influenced by factors related to the mother-baby dyad, the efficacy of intervention measures for BF support depends on the identification of risk factors for the cessation of EBF [10, 26].

Considering the above considerations, the objective of the present study was to determine which gestational, perinatal, and postnatal factors of the mother-baby dyad might be associated with the cessation of EBF by six months after birth. It is speculated that if such associations are confirmed, it will be possible to enrich prenatal and postnatal counseling to encourage EBF for a period of six months postpartum. Finally, we also sought to identify information that may help increase the prevalence of EBF in Brazil.

\section{Methods \\ Study design}

Data from this observational, analytical, and longitudinal study were collected in two stages. The baseline data collection involved the inpatient facility of the CRSMMater from December 2012 to April 2013. The followup data collection consisted of telephone contact between researchers and the participating mothers in the six months completed after the birth date (i.e., from May to September 2013).

In baseline data collection, clinical and sociodemographic information of the mother-baby dyad were collected through the application of a previously established questionnaire composed of open questions (see Additional file 1). When questioned about their previous experience with $\mathrm{BF}$ the mothers were provided a definition of EBF by the researcher conducting the interview. The interview of the participating mothers occurred in the joint housing of the CRSM - Mater during the postpartum period (24 to $72 \mathrm{~h}$ after birth) prior to discharge. In addition, the information contained in the questionnaire was confirmed using the records of the mother of the baby. Furthermore, information that the mothers were unable to answer was obtained through the clinical registry.

In follow-up data collection, a telephonic survey of the participating mothers was conducted by the researcher at six months after birth. This survey used a questionnaire to identify the type of feeding practiced at that time (see Additional file 2). This questionnaire was composed of two questions. In the first question, the mother was asked the following question regarding their practice of BF: Does your child ever breastfeed? In the case of a negative answer, it was considered that mother and baby no longer practiced $\mathrm{BF}$, including EBF. In the case of a positive response, the investigator then informed the mother about the following definition of EBF, as indicated by the World Health Organization: EBF means that the baby receives only breast milk directly from the breast or pumped, or HM from another source, without any other liquids or solids, except for drops or syrups containing vitamins, oral rehydration salts, mineral supplements, or medications [27]. Next, the mother was questioned about their practice of EBF in the last $24 \mathrm{~h}$ : "Given the definition of EBF, do you practice EBF?" In the case of a negative answer, it was considered that mother and baby no longer practiced EBF. In subsequent 
statistical analyses, this answer was considered to indicate the cessation of EBF. In the case of a positive response, the mother was considered to be practicing EBF by six months after birth.

\section{Sample size}

The sample size was calculated using the POWER procedure of the SAS 9.2 software and EBF prevalence rate of $11.5 \%$ related to $5-6$ months infants born in Ribeirão Preto in 2011 [28]. Considering the birth of 1870 infants in the CRSM-Mater in the last six months from the study planning date, it was possible to assume prevalence rates and absolute errors (0.05) based on a 95\% confidence level and thus estimate the sample size. Assuming that there would be a $10 \%$ loss of contact with the subjects interviewed six months after the date of birth, the sample size should be approximately 160 dyads. However, considering that the CRSM-Mater is intended to assist the female population that uses the National Health Unified System in Ribeirão Preto and some cities in the region, we decided to increase size of the sample since we assumed that we would lose contact with more than $10 \%$ of patients. Dyads were recruited and evaluated over a period of four months using the inclusion criteria for the first phase of data collection in the Maternal and Child Health Centers.

\section{Inclusion criteria}

The babies selected for this study were only healthy, singleton term infants with a gestational age of 37 to 42 weeks who were born to healthy mothers with no gravidic-puerperal intercurrences that might prevent or hamper being breastfed $[29,30]$.

After the selection of the participating mothers and infants in the first stage of the study, the effective inclusion of these patients occurred after the researcher contacted the participating mother or legal guardian, in the case of adolescent mothers, provided information about the study procedures, and confirmed the interest of the mother in BF her child. Then, researchers obtained written informed consent.

\section{Statistical analysis}

Data were analyzed statistically by fitting log-binomial regression models using SAS 9.3. Outcomes were defined as the cessation of EBF by six months after birth and the remaining gestational, perinatal, and postnatal factors of the mother-baby dyad were defined as independent variables. To test the associations between outcome and independent variables, a theoretical hierarchical model was proposed to stratify the relationship between variables and outcomes, as presented in Table 1. Therefore, the independent variables were arranged in hierarchical levels established according to the proximity of the outcome according to literature data [31]. Thus, four hierarchical levels were established: distal level, intermediate distal level, intermediate proximal level, and proximal level.

In the statistical analysis, the variables of each level were adjusted in relation to the remaining variables of the same level and in relation to the variables present in the preceding hierarchical level. Thus, the variables of the distal intermediate level were adjusted in relation to the variables of the same level and in relation to the variables of the distal level. This process continued through the proximal level until the association of the variables with the outcome was established.

\section{Results}

During the baseline data collection in the CRSM-Mater, 400 dyads were interviewed. After six months, during the follow-up data collection, telephone contact was possible and established with only 283 dyads. Thus, the loss of contact with the dyads was $29.25 \%$.

The gestational, perinatal, and postnatal variables of the 283 dyads in the two research stages are presented in Table 2 and described below.

The participating mothers were 14 to 49 years of age, with $210(74.2 \%)$ of the 283 mothers being 20 years of age or older; $203(71.7 \%)$ reporting schooling of more than 8 years, and 167 (59.0\%) reporting that they did not perform any type of remunerated activity until birth.

Table 1 Variables organized according to the temporal proximity to outcome

\begin{tabular}{|c|c|c|c|c|}
\hline Distal level & Intermediate distal level & Proximal intermediate level & Proximal level & Outcome \\
\hline $\begin{array}{l}\text { Maternal sociodemographic } \\
\text { variables }\end{array}$ & Prenatal care variables & $\begin{array}{l}\text { Variables related to the } \\
\text { period of delivery }\end{array}$ & Postnatal variables & $\begin{array}{l}\text { Cessation of EBF by six } \\
\text { months after birth }\end{array}$ \\
\hline - Maternal age & $\begin{array}{l}\text { - Planning of the last } \\
\text { pregnancy }\end{array}$ & - Number of pregnancies & $\begin{array}{l}\text { - Time of first baby } \\
\text { suckling after birth }\end{array}$ & \\
\hline - Maternal schooling & $\begin{array}{l}\text { - Number of prenatal } \\
\text { visits attended }\end{array}$ & - Period of birth & $\begin{array}{l}\text { - Initial maternal difficulty } \\
\text { with BF }\end{array}$ & \\
\hline - Remunerated activity performed & $\begin{array}{l}\text { - Maternal prenatal } \\
\text { guidance about BF }\end{array}$ & - Classification of birth & $\begin{array}{l}\text { - Maternal guidance about } \\
\text { BF after birth }\end{array}$ & \\
\hline \multicolumn{5}{|l|}{$\begin{array}{l}\text { - Maternal experience with EBF for } \\
\text { at least one month }\end{array}$} \\
\hline $\begin{array}{l}\text { - Maternal experience with EBF for } \\
\text { at least six months }\end{array}$ & & & & \\
\hline
\end{tabular}


Table 2 Variables of the mother-baby dyads $(n=283)$ enrolled in this study

\begin{tabular}{|c|c|c|c|c|}
\hline Variables of the mother-baby dyad & Total & $\%$ & Practicing $\mathrm{EBF}^{\mathrm{a}}$ & Cessation of $\mathrm{EBF}^{\mathrm{b}}$ \\
\hline \multicolumn{5}{|l|}{ Maternal age at birth } \\
\hline$\leq 20$ years & 73 & 25.8 & 7 & 66 \\
\hline$>20$ years & 210 & 74.2 & 36 & 174 \\
\hline \multicolumn{5}{|l|}{ Maternal schooling immediately after birth } \\
\hline$\leq 8$ complete years of study & 80 & 28.3 & 13 & 67 \\
\hline$>8$ complete years of study & 203 & 71.7 & 30 & 173 \\
\hline \multicolumn{5}{|c|}{ Remunerated activity performed by the mother until birth } \\
\hline No & 167 & 59.0 & 30 & 137 \\
\hline Yes & 116 & 41.0 & 13 & 103 \\
\hline \multicolumn{5}{|l|}{ Number of pregnancies } \\
\hline Primigestae & 121 & 42.8 & 12 & 109 \\
\hline Multigestae & 162 & 57.2 & 31 & 131 \\
\hline \multicolumn{5}{|c|}{ Maternal experience with EBF for at least one month before birth } \\
\hline No & 152 & 53.7 & 17 & 135 \\
\hline Yes & 131 & 46.3 & 26 & 105 \\
\hline \multicolumn{5}{|c|}{ Maternal experience with EBF for at least six months before birth } \\
\hline No & 216 & 76.3 & 24 & 192 \\
\hline Yes & 67 & 23.7 & 19 & 48 \\
\hline \multicolumn{5}{|l|}{ Planning of the last pregnancy } \\
\hline No & 197 & 69.6 & 31 & 166 \\
\hline Yes & 86 & 30.4 & 12 & 74 \\
\hline \multicolumn{5}{|l|}{ Number of prenatal visits attended } \\
\hline$<\operatorname{six}$ & 38 & 13.4 & 4 & 34 \\
\hline$\geq \operatorname{six}$ & 245 & 86.6 & 39 & 206 \\
\hline \multicolumn{5}{|l|}{ Maternal prenatal guidance about BF } \\
\hline No & 147 & 51.9 & 23 & 124 \\
\hline Yes & 136 & 48.1 & 20 & 116 \\
\hline \multicolumn{5}{|l|}{ Period of birth } \\
\hline Daytime & 143 & 50.5 & 15 & 128 \\
\hline Nighttime & 140 & 49.5 & 28 & 112 \\
\hline \multicolumn{5}{|l|}{ Classification of birth } \\
\hline Cesarean & 111 & 39.2 & 16 & 95 \\
\hline Vaginal & 172 & 60.8 & 27 & 145 \\
\hline \multicolumn{5}{|l|}{ Time of first baby suckling after birth } \\
\hline During the first hour of life or before & 109 & 38.5 & 17 & 92 \\
\hline After the first hour of life & 174 & 61.5 & 26 & 148 \\
\hline \multicolumn{5}{|l|}{ Initial maternal difficulty with BF } \\
\hline No & 206 & 72.8 & 38 & 168 \\
\hline Yes & 77 & 27.2 & 5 & 72 \\
\hline \multicolumn{5}{|l|}{ Maternal guidance about BF after birth } \\
\hline No & 12 & 4.2 & 2 & 10 \\
\hline Yes & 271 & 95.8 & 41 & 230 \\
\hline
\end{tabular}

${ }^{a}$ Mothers who responded positively to EBF practice in the last $24 \mathrm{~h}$

${ }^{\mathrm{b}}$ Mothers who responded negatively to EBF practice in the last $24 \mathrm{~h}$ 
Clinical data collected immediately after childbirth revealed that $162(57.2 \%)$ of the participating puerperal women were multigestae, 152 (53.7\%) had no experience with EBF for at least one month, and 216 (76.3\%) had no experience with EBF for at least six months.

In addition, 197 (69.6\%) of the puerperal woman had not planned the last pregnancy, 245 (86.6\%) participated in six or more prenatal visits, and 147 (51.9\%) reported having received no guidance regarding BF during their prenatal care.

Perinatal clinical data showed that 143 (50.5\%) neonates were born during the daytime period, 172 (60.8\%) were born by vaginal birth, and $174(61.5 \%)$ were breastfed for the first time only after the first hour of life.

A total of 206 (72.8\%) did not report initial difficulties with $\mathrm{BF}$ and 271 (95.8\%) reported having received BF instructions after birth.

After the telephone contact in the exact sixth month after the birth date of each participating baby, 43 (15.2\%) mothers reported practicing EBF, however 240 (84.8\%) mothers reported no more exclusively breastfeeding.

After statistical analysis of the data, the unadjusted logistic regression analysis indicated that the factors "Multigestae," "experience with EBF for at least one month," "experience with EBF for at least six months," and "birth during the nighttime period" were associated with cessation of EBF by six months after birth; however, they behaved as protective factors for EBF, as presented in Table 3. The factor "mother reported difficulty with BF" was shown to be a risk factor for the cessation of EBF (Table 3).

Statistical analysis using the proposed theoretical hierarchical model (Table 3) revealed that only one variable was found to be associated with the outcome after adjustment according to the remaining variables. The results indicated that previous experience with EBF for at least six months before the birth reported by the mothers represented a protective factor EBF (i.e., the lack of previous maternal experience with EBF for at least six months is a risk factor for the cessation of EBF by six months after birth).

\section{Discussion}

The present study was conducted in the city of Ribeirão Preto (SP) from 2012 to 2013 to evaluate 283 motherbaby dyads. In doing so, we detected a $15.2 \%$ prevalence of EBF among six-month-old babies (Table 2). A crosssectional study conducted in Ribeirão Preto (SP) two years earlier revealed an EBF prevalence of $11.5 \%$ among 916 infants aged five to six months [28]. Despite detecting a positive difference in EBF rate, the prevalence of EBF in the city of Ribeirão Preto (SP), as well as in Brazil more generally, is still low and worrisome [2, 12, 32].

Several authors support and justify the reasons why it would be important to establish and maintain $\mathrm{BF}$,

Table 3 Logistic regression analysis using the theoretical hierarchical model proposed to stratify the variables (Table 1)

\begin{tabular}{|c|c|c|c|c|c|}
\hline \multirow[t]{2}{*}{ VariablesVariables } & $\begin{array}{l}\text { Crude Relative } \\
\text { Risk }\end{array}$ & Distal level & $\begin{array}{l}\text { Intermediate } \\
\text { distal level }\end{array}$ & $\begin{array}{l}\text { Intermediate } \\
\text { proximal level }\end{array}$ & $\begin{array}{l}\text { Proximal } \\
\text { level }\end{array}$ \\
\hline & CRR $(95 \% \mathrm{Cl})$ & $\mathrm{RR}^{*}(95 \% \mathrm{Cl})$ & $\operatorname{RR}^{*}(95 \% \mathrm{Cl})$ & $\mathrm{RR3}^{\mathrm{a}}(95 \% \mathrm{Cl})$ & $\operatorname{RR}^{*}(95 \% \mathrm{Cl})$ \\
\hline - Maternal age $>20$ years & $0.91(0.83,1.01)$ & $0.94(0.83,1.06)$ & - & - & - \\
\hline $\begin{array}{l}\text { - Maternal schooling >8 } \\
\text { complete years }\end{array}$ & $1.02(0.91,1.14)$ & $0.98(0.88,1.10)$ & - & - & - \\
\hline $\begin{array}{l}\text { - Remunerated activity } \\
\text { performed }\end{array}$ & $1.08(0.98,1.19)$ & $1.09(0.97,1.21)$ & - & - & - \\
\hline - Multigestae & $0.9(0.82,0.98)$ & - & - & $0.97(0.83,1.15)$ & - \\
\hline $\begin{array}{l}\text { - Experience with EBF for at } \\
\text { least one month }\end{array}$ & $0.91(0.81,0.99)$ & $1.01(0.91,1.12)$ & - & - & - \\
\hline $\begin{array}{l}\text { - Experience with EBF for at } \\
\text { least six months }\end{array}$ & $0.81(0.68,0.94)$ & $0.85(0.73,0.99)$ & - & - & - \\
\hline - Last pregnancy was planned & $1.02(0.92,1.13)$ & - & $1.01(0.91,1.13)$ & - & - \\
\hline$\cdot \geq$ six prenatal visits & $0.94(0.83,1.06)$ & - & $0.94(0.76,1.16)$ & - & - \\
\hline $\begin{array}{l}\text { - Mother reported that she did } \\
\text { not receive prenatal guidance regarding BF }\end{array}$ & $0.99(0.9,1.09)$ & - & $0.99(0.89,1.11)$ & - & - \\
\hline - Birth during the nighttime period & $0.89(0.81,0.98)$ & - & - & $0.95(0.85,1.06)$ & - \\
\hline - Cesarean & $1.02(0.92,1.12)$ & - & - & $1.00(0.89,1.12)$ & - \\
\hline $\begin{array}{l}\text { - First suckling occurred after } \\
\text { the first hour of life }\end{array}$ & $1.01(0.91,1.12)$ & - & - & - & $0.99(0.84,1.16)$ \\
\hline - Mother reported difficulty with BF & $1.15(1.05,1.25)$ & - & - & - & $1.04(0.91,1.20)$ \\
\hline - Mother received guidance about BF & $1.02(0.79,1.32)$ & - & - & - & $1.01(0.76,1.32)$ \\
\hline
\end{tabular}

e Relative Risk

$R R^{*}$ Adjusted Relative Risk

95\% Cl 95\% Confidence Interval 
particularly EBF, until the sixth month after birth. However, in view of the low BF rates in Brazil as a whole, these reasons are not sufficient to protect and promote BF practice [20, 33-36].

Several studies have emphasized their concern regarding the early interruption of the practice of BF in Brazil, particularly EBF, and point out possible associated factors, such as early motherhood, maternal educational level, mothers' socioeconomic situation, maternal work outside home, parity, and lack of maternal knowledge about BF [28, 37-44]. In addition, the scientific literature reports that factors, such as number of pregnancies, pregnancy-planning, type of birth, and birth period, are also associated with BF establishment and maintenance before birth [26, 39, 45-47].

In the present study, unadjusted analysis revealed that a larger number of previous pregnancies were protective of the maintenance of EBF in the sixth month, (Table 3). Previous studies have reported that multiparous mothers and multigestae are more likely to perform BF than are primiparous mothers. They further demonstrated that primiparity is associated with an early interruption of BF [39, 48-52]. A study that conducted logistic regression analysis in order to test the association of risk factors with weaning reported that primiparous mothers had a greater risk of not providing EBF at 120 and 180 days after delivery. Regarding the period of 180 days after delivery, primiparity was shown to be associated with the interruption of EBF in terms of both gross $(1.87 ; 95 \% \mathrm{CI}$ $1.08,3.24)$ and adjusted $(2.20 ; 95 \%$ CI 1.14, 4.25) odds ratio [48].

One possible explanation for the association of parity with EBF is the role of previous maternal experience with BF. Studies have reported that women with previous BF experience have a greater chance of exclusively BF their babies in the first six months after birth [42]. A cohort study conducted on 1309 mother-baby dyads determined that the lack of previous BF experience was associated with the interruption of EBF as early as during the first month after birth $(1.24 ; 95 \%$ CI $1.75,1.43)$ [44].

In this study, we found that there was a significant association between cessation of EBF and maternal report of previous experience with EBF for one month (0.91, $95 \%$ CI $0.81,0.99)$ and six months $(0.81 ; 95 \%$ CI 0.68 , $0.94)$. These practices were associated with the maintenance of EBF and, even after adjustment for maternal socio-demographic variables, this association was maintained $(0.85 ; 95 \%$ CI $0.73,0.99)$, as presented in Table 3. Thus, there is a greater chance of practicing and maintaining EBF until the sixth month after birth when mother had previous experience with it.

Despite the evidence obtained in the present study, a systematic review of epidemiological studies conducted in Brazil between 1998 and 2010, specifically 20 crosssectional studies and 7 cohort studies, identified 36 factors associated with EBF. However, only two studies reported the association between prior maternal experiences with EBF by six months after birth [31]. In addition to this systematic review, a recent cohort study that was conducted in a city in the Northeast of Brazil in an effort to identify factors associated with the cessation of EBF did not find an association between the absence of prior BF experience and the cessation of EBF by six months after birth [53].

However, in addition to what has already been advocated, a recent study found that previous maternal experience with $\mathrm{BF}$ of the first child might determine the practice of BF the second child. However, the authors emphasized that mothers who had initial difficulties with BF their first child were less likely to initiate BF of the second child. Therefore, it is necessary to deal with the difficulties and quality of BF practice of their first child to ensure that the next child will be properly breastfed [54].

Therefore, we believe that it is important to emphasize that 152 and 216 mothers participating in our study reported that they did not have prior experience with EBF for one and six months, respectively. Because our sample comprised 121 primiparous women, who did not really have the possibility of previous BF experience, a higher number of mothers interviewed reported that they did not have such experience, which shows that some of the multigestae had no previous experience with EBF. Thus, we believe that previous experience with EBF influences $\mathrm{BF}$ practice and that the evaluation of the quality of this experience is necessary. Furthermore, it is important to evaluate the difficulties related to the process of BF previous children.

Regarding difficulties with BF, we did not question the reported previous difficulties with BF because its reporting was subjective and could have biased this study. However, we questioned the mother about initial difficulties with the current child's BF but without detailing such a variable. After performing the unadjusted analysis of the data, responses to "initial maternal difficulty with BF" was associated with cessation of EBF by six months after birth (Table 3). Difficulties related to BF and inadequate practice of BF techniques are among the main reasons why mothers wean their children, thereby reinforcing the importance of specialized professional support to assist in the establishment and maintenance of BF $[55,56]$.

Finally, based on previous reports, the specialized support of health care professionals and the support of family members are fundamental to the practice of BF $[57,58]$. Studies have indicated that the presence of the mother's partner is associated with EBF practice during the first six months after childbirth and that better marital stability is related to a lower chance of early weaning [40, 41]. In 
addition, a systematic review showed improvement in EBF rates following individual and group interventions that supported BF [59]. Educational interventions, such as the Baby Friendly Initiative, that support, promote, and protect BF while simultaneously involving sectors, such as the home, community, and health system, have facilitated improvements in BF rates, particularly EBF, and favor the maintenance of this practice $[60,61]$.

We found an interesting association between the variable "period of birth" and the cessation of EBF. Possible speculation about night time birth as a protective factor for EBF could be the nature of the hospital environment, which is routinely calmer at night. This could more easily allow for skin-to-skin contact and BF during the first hour of life. In addition, visitors are only allowed to visit during the day, which may interfere with BF practice $[62,63]$.

\section{Limitations}

The study presented some limitations such as the fact that information needed to justify the findings had not been collected, since there were dyads invited to participate in the study who refused the invitation after being informed of the procedures. In addition, the relatively small sample size and the restriction to a single data collection site can also be considered limiting factors of this study.

\section{Conclusions}

The support of health professionals and society at large is essential to advocate the importance of EBF practice. However, being aware of the benefits and advantages of $\mathrm{BF}$ and opting for this practice are not enough to establish and maintain $\mathrm{BF}$ for an appropriate period.

It is important not to generalize the ability to breastfeed and to consider the variables involved in the BF process. Therefore, it is essential to promptly identify the risk variables associated with the early interruption of EBF, thereby contributing to the efficacy of intervention measures for the support of EBF during the first six months after birth. Our study allowed the identification of risk variables associated with the cessation of EBF by six months after birth, such as the previous experience with exclusive breastfeeding. We believe that the identification and consideration of variables associated with EBF cessation may contribute to the effectiveness of intervention and support measures related to breastfeeding.

When favorable interventions that promote BF are performed with consideration of different determinants of BF practice, EBF is more frequently practiced. This fact can provide economic and environmental advantages for children, women, and society, such as the reduction in health care costs [10].

\section{Additional files}

Additional file 1: Description of data: Clinical and sociodemographic information of the mother-baby dyad were collected through the application of this previously established questionnaire composed of open questions. (DOCX $13 \mathrm{~kb}$ )

Additional file 2: Questionnaire used in the sixth month. Description of data: In follow-up data collection, this survey used this questionnaire composed of two questions to identify the type of feeding practiced at that time. (DOCX $17 \mathrm{~kb})$

\section{Abbreviations \\ BF: Breastfeeding; CRSM-Mater: Reference Center for Women's Health in Ribeirão Preto-Mater; EBF: Exclusive breastfeeding; HM: Human milk}

\section{Acknowledgements}

We thank CAPES (Coordination of Improvement of Higher Education Personnel) for financial support (MMO Master of Science scholarship).

Funding

CAPES (Coordination of Improvement of Higher Education Personnel - Brazil) supported this research.

\section{Availability of data and materials}

The datasets collected and/or analyzed during the current study are available from the corresponding author upon reasonable request.

\section{Authors' contributions}

All authors were involved in the planning of this study. MMO designed the study, collected and analyzed data with the technical support of the statistician and wrote the final manuscript. All authors reviewed and approved the final manuscript for submission.

Ethics approval and consent to participate

The study and the "Free and Informed Consent Form" were approved by the Research Ethics Committee of the Clinics Hospital of Ribeirão Preto in accordance with documents numbers 1812/2011 and 2036/2011. The Research Committee of the Reference Center for Women's Health in Ribeirão Preto-Mater (CRSM-Mater) authorized data collection in accordance with document number 012/2011. All participants signed the "Free and Informed Consent Form" and formally confirmed their participation.

Consent for publication

Not applicable.

Competing interests

The authors declare that they have no competing interests.

\section{Publisher's Note}

Springer Nature remains neutral with regard to jurisdictional claims in published maps and institutional affiliations.

Received: 21 January 2017 Accepted: 11 September 2017

Published online: 03 October 2017

References

1. American Academy of Pediatrics. Breastfeeding and the use of human milk. Pediatrics. 2012;129(3):e827-41.

2. Brasil. Ministério da Saúde. Pesquisa Nacional de Demografia e Saúde da criança e da mulher: PNDS 2006: dimensões do processo reprodutivo e da saúde da criança: Amamentação e alimentação infantil. Brasília: Centro Brasileiro de Análise e Planejamento; 2009. Disponível em: (http://bvsms. saude.gov.br/bvs/publicacoes/pnds_crianca_mulher.pdf)

3. Castilho SD, Barros Filho AA. The history of infant nutrition. J Pediatr. 2010; 86(3):179-88.

4. Horta BL, De Mola CL, Victora CG. Breastfeeding and intelligence: systematic review and meta-analysis. Acta Paediatr. 2015;104(467):14-9. 
5. Imdad A, Yakoob MY, Bhutta ZA. Effect of breastfeeding promotion interventions on breastfeeding rates, with special focus on developing countries. BMC Public Health. 2011;11(Suppl 3):S24.

6. World Health Organization. Global Strategy on Infant and Young Child Feeding. Geneva: World Health Organization; 2003.

7. Imdad A, Yakoob MY, Bhutta ZA. Impact of maternal education about complementary feeding and provision of complementary foods on child growth in developing countries. BMC Public Health. 2011;11(Suppl 3):S25.

8. Monte CMG, Giugliani ERJ. Recommendations for the complementary feeding of the breastfed child. J Pediatr. 2004;80(5 Suppl):S131-41.

9. WHO, PAHO. Guiding Principles for Complementary Feeding of the Breastfed Child. Washington: World Health Organization; 2003.

10. Rollins NC, Bhandari N, Hajeebhoy N, Horton S, Lutter CK, Martines JC, Piwoz EG, Richter LM, Victora CG. Why invest, and what it will take to improve breastfeeding practices? Lancet. 2016;387(10017):491-504

11. Stuebe A. The risks of not breastfeeding for mothers and infants. Rev Obstet Gynecol. 2009;2(4):222-31.

12. Sena MCF, Silva EF, Pereira MG. Prevalence of breastfeeding in Brazilian capital cities. Rev Assoc Med Bras. 2007:53(6):520-4

13. Bai DL, Fong DY, Tarrant M. Factors associated with breastfeeding duration and exclusivity in mothers returning to paid employment postpartum. Matern Child Health J. 2015;19(5):990-9.

14. Ogbuanu C, Glover S, Probst J, Liu J, Hussey J. The effect of maternity leave length and time of return to work on breastfeeding. Pediatrics. 2011;127(6):e1414-27.

15. Stevens EE, Patrick TE, Pickler R. A history of infant feeding. J Perinat Educ. 2009;18(2):32-9.

16. Akre J. Infant feeding. The Physiological Basis. Bull World Health Organ. 1989;67(Suppl):1-108.

17. Toma TS, Rea MF. Benefits of breastfeeding for maternal and child health: an essay on the scientific evidence. Cad Saude Publica. 2008:24(Suppl 2):S235-46.

18. Horta BL, De Mola CL, Victora CG. Long-term consequences of breastfeeding on cholesterol, obesity, systolic blood pressure, and type 2 diabetes: systematic review and meta-analysis. Acta Paediatr. 2015;104(467):30-7.

19. Richards M, Hardy R, Wadsworth MEJ. Long-term effects of breast-feeding in a national birth cohort: educational attainment and midlife cognitive function. Public Health Nutr. 2002;5(5):631-5.

20. Victora CG, Bahl R, Barros AJD, França GVA, Horton S, Krasevec J, Murch S, Sankar MJ, Walker N, Rollins NC. Breastfeeding in the 21st century: epidemiology, mechanisms, and lifelong effect. Lancet. 2016;387(10017):475-90.

21. Walker WA, lyengar RS. Breast milk, microbiota, and intestinal immune homeostasis. Pediatr Res. 2015;77(1-2):220-8.

22. Almeida JAG, Novak FR. Breastfeeding: a nature-culture hybrid. J Pediatr. 2004;80(5 Suppl):S119-25

23. Marques NM, Lira Pl, Lima MC, Silva NL, Filho MB, Huttly SR, Ashworth A. Breastfeeding and early weaning practices in northeast Brazil: a longitudinal study. Pediatrics. 2001;108(4):E66.

24. Dubois L, Girard M. Social determinants of initiation, duration and exclusivity of breastfeeding at the population level: the results of the Longitudinal Study of Child Development in Quebec (ELDEQ 1998-2002). Can J Public Health. 2003;94(4):300-5

25. Li R, Fein SB, Chen J, Grummer-Strawn LM. Why mothers stop breastfeeding: mothers' self-reported reasons for stopping during the first year. Pediatrics. 2008;122(2 Suppl):S69-76.

26. Weiderpass E, Barros FC, Victora CG, Tomasi E, Halpern R. Incidence and duration of breast-feeding by type of delivery: a longitudinal study in southeastern of Brazil. Rev Saude Publica. 1998:32(3):225-31.

27. World Health Organization. Evidence on the Long-term Effects of Breastfeeding: Systematic Review and Meta-analyses. Geneva: World Health Organization; 2007.

28. Passanha A, Benício MHD, Venâncio SI, Reis MCG. Implementation of the Brazilian Breastfeeding Network and prevalence of exclusive breastfeeding Rev Saude Publica. 2013:47(6):1141-8.

29. Capurro H, Korichzky S, Fonseca O, Caldeiro-Barcia R. A simplified method for diagnosis of gestational age in the newborn infant. J Pediatr. 1978;93(1):120-2.

30. Whitworth M, Bricker L, Mullan C. Ultrasound for fetal assessment in early pregnancy. Cochrane Database Syst Rev. 2015;14(7):CD007058.

31. Boccolini CS, Carvalho ML, Oliveira MIC. Factors associated with exclusive breastfeeding in the first six months of life in Brazil: a systematic review. Rev Saude Publica. 2015;49:91.

32. Brasil. Ministério da Saúde. Secretaria de Atenção à Saúde: Departamento de Ações Programáticas e Estratégicas: II Pesquisa de Prevalência de
Aleitamento Materno nas Capitais Brasileiras e Distrito Federal, Brasilia; 2009. Disponível em: (http://bvsms.saude.gov.br/bvs/publicacoes/pesquisa_ prevalencia_aleitamento_materno.pdf)

33. Howie PW, Forsyth JS, Ogston SA, Clark A, Florey CV. Protective effect of breast-feeding against infection. BMJ. 1990;300(6716):11-6.

34. Kramer MS, Kakuma R. The optimal duration of exclusive breastfeeding: a systematic review. Adv Exp Med Biol. 2004:554:63-77.

35. Novak FR, Almeida JAG, Vieira GO, Borba LM. Human colostrum: a natural source of probiotics? J Pediatr. 2001;77(4):265-70.

36. Sankar MJ, Sinha B, Chowdhury R, Nita Bhandari N, Taneja S, Martines J, Bahl R. Optimal breastfeeding practices and infant and child mortality: a systematic review and meta-analysis. Acta Paediatr. 2015;104(467):3-13.

37. Ahluwalia IB, Morrow B, Hsia J. Why do women stop breastfeeding? Findings from the Pregnancy Risk Assessment and Monitoring System. Pediatrics. 2005;116(6):1408-12

38. Jara-Palacios MÁ, Cornejo AC, Peláez GA, Verdesoto J, Galvis AA. Prevalence and determinants of exclusive breastfeeding among adolescent mothers from Quito, Ecuador: a cross-sectional study. Int Breastfeed J. 2015;10:33.

39. Gigante DP, Victora CG, Barros FC. Maternal nutrition and duration of breastfeeding in a birth cohort in Pelotas, Brazil. Rev Saude Publica. 2000; 34(3):259-65.

40. Li R, Darling N, Maurice E, Barker L, Grummer-Strawn L. Breastfeeding rates in the United States by characteristics of the child, mother or family: the 2002 National Immunization Survey. Pediatrics. 2005;115(1):e31-7.

41. Merten S, Dratva J, Ackermann-Liebrich U. Do baby-friendly hospitals influence breastfeeding duration on a national level? Pediatrics. 2005;116(5):e702-8.

42. Pereira RSV, Oliveira MIC, Andrade CLT, Brito AS. Factors associated with exclusive breastfeeding: the role of primary health care. Cad Saude Publica. 2010;26(12):2343-54

43. Tarrant M, Fong DY, Wu KM, Lee IL, Wong EM, Sham A, Lam C, Dodgson JE. Breastfeeding and weaning practices among Hong Kong mothers: a prospective study. BMC Pregnancy Childbirth. 2010;10:27.

44. Vieira GO, Martins CC, Vieira TO, Oliveira NF, Silva LR. Factors predicting early discontinuation of exclusive breastfeeding in the first month of life. J Pediatr. 2010;86(5):441-4

45. Prior E, Santhakumaran S, Gale C, Philipps LH, Modi N, Hyde JM. Breastfeeding after cesarean delivery: a systematic review and meta-analysis of world literature. Am J Clin Nutr. 2012:95(5):1113-35.

46. Scott J, Binns C, Oddy W, Graham K. Predictors of breastfeeding duration: evidence from a cohort study. Pediatrics. 2006;117(4):e646-55.

47. Ulep VGT, Borja MP. Association between pregnancy intention and optimal breastfeeding practices in the Philippines: a cross-sectional study. BMC Pregnancy Childbirth. 2012;12:69.

48. França GVA, Brunken GS, Silva SM, Escuder MM, Venancio SI. Breast feeding determinants on the first year of life of children in a city of Midwestern Brazil. Rev Saude Publica. 2007;41(5):711-8.

49. Gusmão AM, Béria JU, Gigante LP, Leal AF, Schermann LB. The prevalence of exclusive breastfeeding and associated factors: a cross-sectional study of teenage mothers between 14 and 16 years of age in the city of Porto Alegre in the State of Rio Grande do Sul, Brazil. Cien Saude Colet. 2013; 18(11):3357-68.

50. Hackman NM, Schaefer EW, Beiler JS, Chelsea M, Rose CM, Pau IM. Breastfeeding outcome comparison by parity. Breastfeed Med. 2015;10(3):156-62.

51. Venancio SI, Escuder MML, Kitoko P, Rea MF, Monteiro CA. Frequency and determinants of breastfeeding in the State of São Paulo. Brazil Rev Saude Publica. 2002;36(3):313-8.

52. Venancio SI, Monteiro CA. Individual and contextual determinants of exclusive breast-feeding in São Paulo, Brazil: a multilevel analysis. Public Health Nutr. 2006;9(1):40-6.

53. Vieira TO, Vieira GO, Oliveira NF, Mendes CMC, Giugliani ERJ, Silva LR. Duration of exclusive breastfeeding in a Brazilian population: new determinants in a cohort study. BMC Pregnancy Childbirth. 2014;14:175.

54. Schafer EJ, Campo S, Colaizy TT, Mulder PJ, Ashida S. Influence of experiences and perceptions related to breastfeeding one's first child on breastfeeding initiation of second child. Matern Child Health J. 2017; https:// doi.org/10.1007/s10995-016-2228-1.

55. Santos KJS, Santana GS, Vieira TO, Santos CAST, Giugliani ERJ, Vieira GO. Prevalence and factors associated with cracked nipples in the first month postpartum. BMC Pregnancy Childbirth. 2016;16:209.

56. Odom EC, Li R, Scanlon KS, Perrine CG, Grummer-Strawn L. Reasons for earlier than desired cessation of breastfeeding. Pediatrics. 2013;131(3):e726-e32. 
57. Laanterä S, Pölkki T, Ekström A, Pietilä A. Breastfeeding attitudes of Finnish parents during pregnancy. BMC Pregnancy Childbirth. 2010;10:79.

58. Nesbitt SA, Campbell KA, Jack SM, Robinson H, PieHM K, Bogdan JC. Canadian adolescent mothers' perceptions of influences on breastfeeding decisions: a qualitative descriptive study. BMC Pregnancy Childbirth. 2012;12:149.

59. Haroon S, Das JK, Salam RA, Imdad A, Bhutta ZA. Breastfeeding promotion interventions and breastfeeding practices: a systematic review. BMC Public Health. 2013;13(Suppl 3):S20.

60. Sinha B, Chowdhury R, Sankar MJ, Martines J, Taneja S, Mazumder S, Rollins N, Bahl R, Bhandari N. Interventions to improve breastfeeding outcomes: a systematic review and meta-analysis. Acta Paediatr. 2015;104(467):114-35.

61. Bartick M, Reinhold A. The burden of suboptimal breastfeeding in the United States: a pediatric cost analysis. Pediatrics. 2010;125(5):e1048-56.

62. Arora S, McJunkin C, Wehrer J, Kuhn P. Major factors influencing breastfeeding rates: Mother's perception of father's attitude and milk supply. Pediatrics. 2000;106(5):E67.

63. Sharma IK, Byrne A. Early initiation of breastfeeding: a systematic literature review of factors and barriers in South Asia. Int Breastfeed J. 2016;11:17.

Submit your next manuscript to BioMed Central and we will help you at every step:

- We accept pre-submission inquiries

- Our selector tool helps you to find the most relevant journal

- We provide round the clock customer support

- Convenient online submission

- Thorough peer review

- Inclusion in PubMed and all major indexing services

- Maximum visibility for your research

Submit your manuscript at www.biomedcentral.com/submit
Biomed Central 